\section{A) Check for updates}

Cite this: Polym. Chem., 2019, 10, 2716

Received 22nd March 2019

Accepted 22nd April 2019

DOI: $10.1039 / c 9 p y 00438 f$

rsc.li/polymers

\title{
Monodisperse, sequence-defined macromolecules as a tool to evaluate the limits of ring-closing metathesis $\uparrow$
}

\author{
Katharina S. Wetzel and Michael A. R. Meier (ID *
}

Sequence-defined macromolecules of uniform size unlock the door to many new applications in polymer chemistry, such as structure/property or structure/activity relationship investigations, which cannot be conducted accurately, if the investigated macromolecules exhibit dispersity. We herein demonstrate a first example by reporting the efficient and template-free synthesis of monodisperse, sequence-defined cyclic oligomers that are significantly larger than conventional large macrocycles (here >150 backbone atoms). Linear monodisperse precursors were utilized to evaluate the limits of ring-closing metathesis (RCM), manifesting clear trends depending on the ring size and introduced side chains. Furthermore, this work is the first example of a sequence-defined synthesis of a polymer architecture other than linear macromolecules.

\section{Introduction}

The field of sequence-control and definition in polymer chemistry has evolved to become one of the hottest topics in polymer chemistry today, as chemists worldwide seek more control over the molecular structure of macromolecules, and it has allowed to develop new applications for well-defined polymers and to correlate structure-property relationships. ${ }^{1}$ Over the last decade, numerous new approaches toward defined macromolecules have been developed, ${ }^{1 a, 2}$ which have paved the road for applications like data storage, ${ }^{3}$ anti-counterfeit tags ${ }^{4}$ or enzyme mimicking catalysts. ${ }^{5}$ As Lutz, Ouchi and Sawamoto defined in 2013, it is crucial to distinguish between the two terms "sequence-controlled" and "sequence-defined" in this context, since only the latter are unique macromolecules (i.e. not showing dispersity in the sequence or molecular weight). ${ }^{6}$ Sequence-controlled polymers, on the other hand, still exhibit distributions in both the building block sequence and macromolecule size $(\nexists>1)^{7}$

Most synthetic approaches toward sequence-defined macromolecules are based on iterative strategies, which form oligomers in a stepwise fashion, either by strategic combination of orthogonal reactions, or by using protecting groups. ${ }^{2 e, 8}$ Multicomponent reactions, like the Passerini three-component reaction (P-3CR) used in this work, have been shown to be a

Karlsruhe Institute of Technology (KIT, Institute of Organic Chemistry (IOC)), Materialwissenschaftliches Zentrum für Energiesyteme (MZE), Straße am Forum 7, 76131 Karlsruhe, Germany. E-mail: m.a.r.meier@kit.edu; http://www.meier-michael.com $\dagger$ Electronic supplementary information (ESI) available: Experimental details and characterization data. See DOI: 10.1039/c9py00438f highly efficient tool to introduce various functionalities to the oligomeric backbone due to their modular character. ${ }^{2 c, d, 3 a, 9}$ P-3CR, which was first discovered in 1921, is a robust and efficient one-pot reaction between an acid, an aldehyde and an isocyanide, providing nearly quantitative yields (see Scheme 1B). ${ }^{10}$

Synthetic investigations on polymer architectures, such as linear polymers, polymer brushes, star polymers, ladder polymers, dendrimers, hyperbranched polymers, and network polymers, have led to an understanding on how the material properties are fundamentally affected by the respective molecular architecture. ${ }^{11}$ Oligomeric, monodisperse macrocycles have gained growing interest due to their characteristic behavior compared to their linear analogs, because the end groups of non-cyclic polymers have demonstrated a significant influence on their properties. ${ }^{12}$ The synthesis of cyclic polymers is classified into two main methods: end-to-end cyclization of linear precursors, which can be further divided into unimolecular reactions of $\alpha, \omega$-heterofunctional polymers ${ }^{13}$ and bimolecular reactions of $\alpha, \alpha^{\prime}$-homodifunctional polymers, ${ }^{14}$ as well as ring-expansion polymerizations. ${ }^{15}$ However, regardless of the mentioned methodology, the macrocycles obtained were either disperse in size, ${ }^{12 b}$ or monodisperse and small in size (ca. 3-13 bonds along the backbone). ${ }^{11}$ In organic chemistry, ringclosing metathesis (RCM) is mostly applied for the preparation of small rings bearing five to seven ring atoms. ${ }^{16}$ However, also larger rings of eight to eleven ring atoms, which are referred to as medium sized rings, are formed by $\mathrm{RCM}^{17}$ and furthermore so-called large macrocycles of 12 to 15 and more ring atoms ${ }^{17}$ or more complex polycyclic systems are obtained. $^{18}$ These monodisperse cycles obtained by RCM 


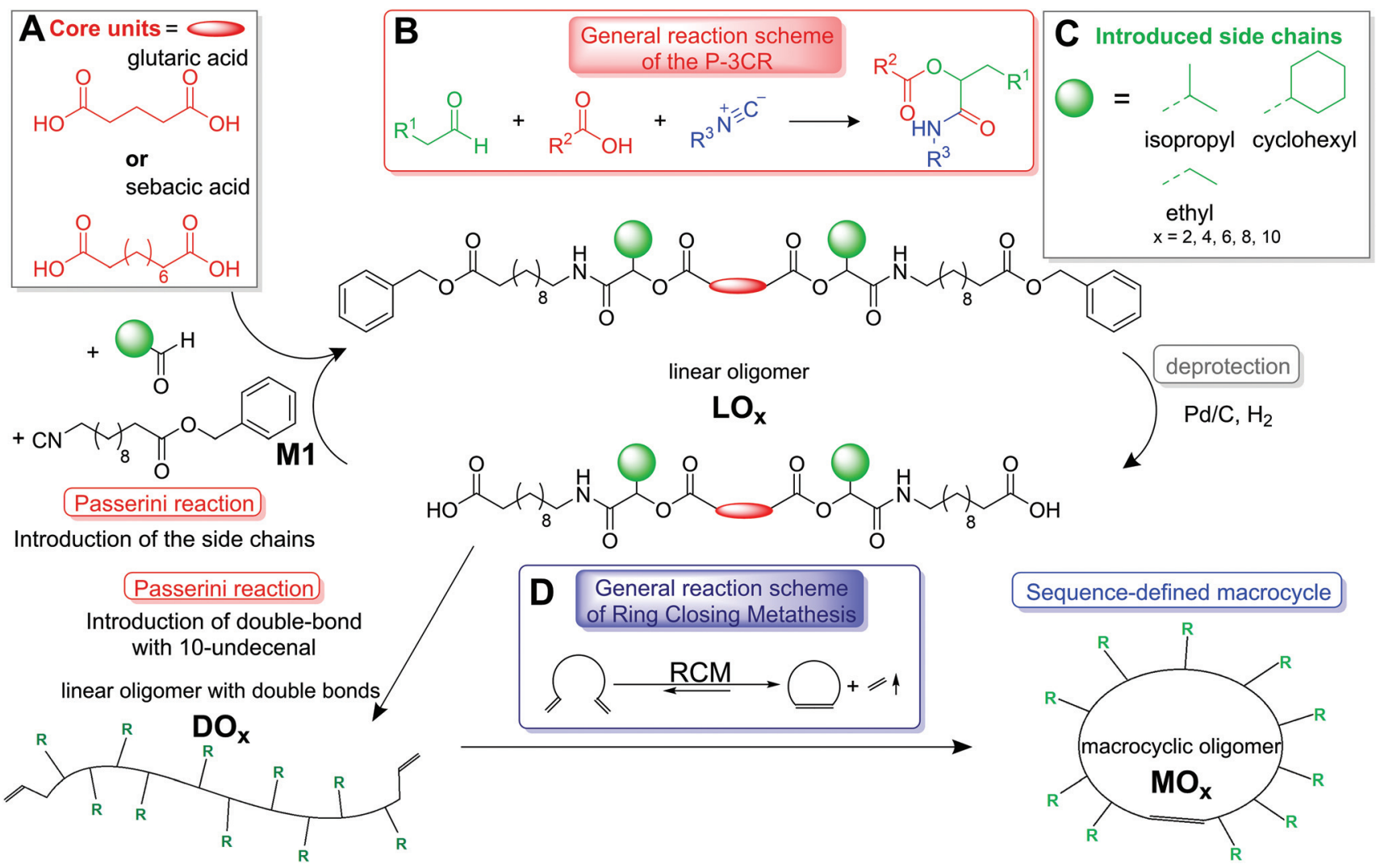

Scheme 1 General reaction scheme for the synthesis of large, monodisperse and sequence-defined macrocycles using bifunctional acids (panel A) as core units. The three different side chains (displayed in panel C) are introduced to the linear macromolecules. The general reaction scheme of the $\mathrm{P}-3 \mathrm{CR}$, which is used to form linear oligomers, is shown in panel B and the general reaction scheme of the RCM, which is used for macrocyclization, is shown in panel $D$.

exhibit versatile structures ${ }^{17,19}$ and the yields vary from very low to nearly quantitative, depending on the substrates. ${ }^{17,19}$ Several examples of macrocyclic biomacromolecules are also known, for instance macrocyclic peptides or DNA are reported. ${ }^{20}$ In cyclic peptides, typically smaller cycles consisting of four to six amino acids are formed, ${ }^{21}$ while examples of ultra large DNA cycles are reported. ${ }^{22}$ Interestingly, such cycles are formed using rigid precursors with an appropriate geometry, which lead to a preorganization and thus easier cyclization. Preorganization of linear precursors by ligands, hydrogen bonds or rigid architectures is a very useful and widely applied concept to achieve an efficient macrocylization. ${ }^{23}$ In contrast, macrocycles with a molecular weight in the range of polymers (for example cyclic polythiolactones with a molecular weight of up to $13 \mathrm{kDa}^{24}$ ) are obtained if disperse polymeric or oligomeric precursors, obtained by controlled radical polymerization (i.e. ATRP polystyrene oligomers with a relatively low PDI $<1.2^{25}$ ), are cyclized. The synthesis of macrocycles, that are both large and monodisperse, in contrast, was especially developed for catenanes,$^{26}$ where the use of a metal ion template, that serves as a ligand coordination site for the linear components, was inevitable. ${ }^{27}$ One interesting exception reported by Alabi and coworkers is an iterative approach towards defined macrocycles consisting of up to 56 ring atoms. ${ }^{28}$

\section{Results and discussion}

\section{Synthesis of symmetric linear oligomers $\left(\mathrm{LO}_{X}\right)$}

We herein present a new, efficient and fast template-free approach toward large sequence-defined macrocycles (up to 152 ring atoms) of uniform size, bearing flexible backbones and tailored side chains. To form sequence-defined macrocycles, linear and symmetric oligomers bearing tailored side chains were first synthesized as precursors. For this purpose, a synthesis protocol, which was previously developed by our group in order to synthesize a sequence-defined icosamer, ${ }^{9 d}$ was adapted. The oligomers were formed in a two-step iterative cycle consisting of P-3CR and a deprotection step. Apart from the monomer (M1), which bears an isocyanide and a benzyl ester protected acid, and which is synthesized in three steps from the corresponding amino acid (see the ESI $\dagger$ for details), ${ }^{9 d}$ all used substances are commercially available. We have previously shown that this strategy leads to the straightforward and high-yielding synthesis of a sequence-defined icosamer. ${ }^{9 d}$ Here, a bifunctional carboxylic acid as the starting material (see Scheme 1A, i.e. bidirectional growth) reduced the overall reaction time. As such, linear oligomers of different

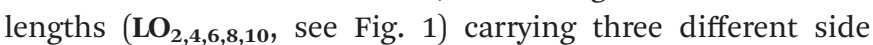
chains (namely ethyl, cyclohexyl or isopropyl, see Scheme 1C) 


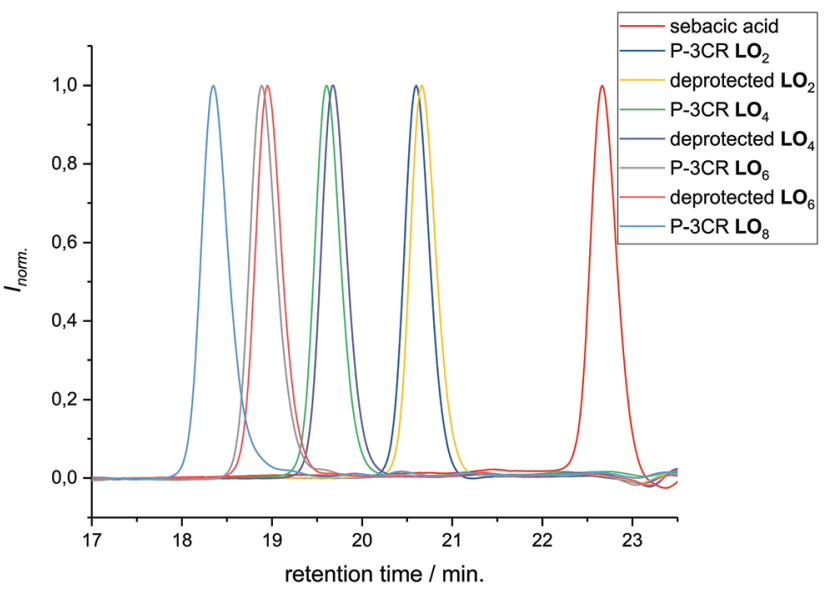

Fig. 1 SEC analysis of the linear oligomers $\left(\mathrm{LO}_{2-8}\right)$ carrying isopropyl side chains. The SEC traces clearly verify the uniform size distribution of the obtained products.

were synthesized. Just as a note for clarity, the formed stereocenters remain undefined and thus a mixture of stereoisomers is formed, as is typical in this young field of research. In the future, it would be of course of high relevance and importance to increase the molecular definition even further by stereoselective synthesis.

Initially, glutaric acid was used as the starting material, but the yield in the first P-3CR was relatively low (69-86\%, depending on the side chain). Thus, glutaric acid was later replaced with the longer sebacic acid leading to significantly increased yields of $97-99 \%$. Four different oligomers were synthesized: two with glutaric acid as the starting material and ethyl or cyclohexyl side chains and two with sebacic acid as the core unit carrying cyclohexyl or isopropyl side chains (see Scheme 1). The P-3CRs were conducted in dichloromethane (DCM) at a concentration of 0.5 M. Monomer M1 and the aldehyde components (propanal, cyclohexane carboxaldehyde or isobutyraldehyde) were added in a small excess (1.5 eq.) relative to the acid groups (3.0 eq. of these components relative to the diacid). After a reaction time of 24 hours, the crude products were purified by column chromatography to obtain the pure dimers in nearly quantitative yields (i.e. 100\% by NMR spectroscopy, 98-99\% purity by SEC, see Fig. 1). The oligomer synthesis was performed on a gram scale (i.e. product $\mathbf{L O}_{\mathbf{8}}$ was obtained with a yield of $2.5 \mathrm{~g}$ ). The products were characterized after each reaction step by ${ }^{1} \mathrm{H},{ }^{13} \mathrm{C}$ NMR, and IR spectroscopy, mass spectrometry and size exclusion chromatography (SEC) to verify the structure of the obtained products and their dispersity (compare Fig. 1 and see the ESI $\dagger$ for the respective set of analytical data of all the obtained products). In the second reaction of the iterative cycle, the benzyl ester protecting groups were removed by hydrogenolysis in a quantitative manner. Upon complete deprotection, a second P-3CR can be performed on account of the newly formed dicarboxylic acid. By applying this iterative strategy, symmetric oligomers of a length up to ten units were synthesized. In the third P-3CR, the reaction time was extended to 48 hours to ensure full con- version, while for the deprotection step, the concentration was decreased with increasing length of the oligomers to address the increased viscosity and ensure full conversion (see the $\mathrm{ESI}^{\dagger}$ for experimental details).

\section{Introduction of terminal double bonds to form $\mathrm{DO}_{X}$}

At different stages of the synthesis, small amounts (300-900 $\mathrm{mg}$ ) of the deprotected oligomers $\left(\mathbf{L O}_{\boldsymbol{x}}\right)$ were separated from the product and were used in one last P-3CR with 10-undecenal, in order to introduce two terminal double bonds to the final linear oligomer $\left(\mathbf{D O}_{\boldsymbol{x}}\right)$. The introduction of the double bonds always marked the final reaction before macrocyclization for the respective oligomer $\mathbf{D O}_{\boldsymbol{x}}$. The remaining $\mathbf{L O}_{\boldsymbol{x}}$ was used to continue the synthesis towards higher molecular weight oligomers, with the introduction of the double bonds taking place at a later stage. Thus, symmetric monodisperse dimers, tetramers, hexamers, octamers, and decamers, containing tailored side chains and terminal double bonds $\left(\mathbf{D O}_{\boldsymbol{x}}\right)$, were obtained.

\section{Ring-closing metathesis to form $\mathrm{MO}_{X}$}

The introduced terminal double bonds were exploited for the formation of sequence-defined macrocycles $\left(\mathbf{M O}_{\boldsymbol{x}}\right)$ via RCM (see Scheme 1D). Grubbs $1^{\text {st }}$ generation catalyst was chosen, since it catalyzes the RCM reaction, while minimizing the ringopening polymerization of the formed cycles. ${ }^{29}$ Furthermore, it does not show olefin isomerization side reactions, which are very pronounced for the $2^{\text {nd }}$ generation catalyst and can only be suppressed to some extent (and would thus lead to dispersity in our system). ${ }^{30}$ Initially, the RCM reaction of a $\mathbf{D O}_{\mathbf{8}}$ carrying cyclohexyl side chains was investigated and the crude product $\left(\mathbf{M O}_{\mathbf{8}}\right)$ was analyzed by SEC-ESI-MS and a relatively low conversion towards the macrocycle of around $32 \%$ was determined. The reaction was thus optimized by adding the same amount (10 mol\%) of catalyst several times during the reaction, thus increasing the total amount of catalyst to $40 \mathrm{~mol} \%$. This catalyst concentration is relatively high, if compared with typical catalyst concentrations of 1-5 mol\% for the synthesis of smaller cycles; however, if larger or highly functionalized molecules were cyclized, also higher catalyst concentrations of 30 or even 60 mol\% are reported. ${ }^{17 a}$ After this optimization, all RCM reactions were performed under identical conditions in order to evaluate the influence of the side chains or the oligomer length on the conversion towards the macrocycle. The reactions were carried out in high dilution (ca. $5 \times 10^{-4} \mathrm{~mol} \mathrm{~L}^{-1}$ in chloroform) in order to prevent acyclic diene metathesis (ADMET), using Grubbs $1^{\text {st }}$ generation catalyst, which was added in four aliquots in the course of the reaction $(4 \times 10 \mathrm{~mol} \%)$. The desired macrocycles were obtained after five hours at $45^{\circ} \mathrm{C}$. Remarkably, the reactivity of the catalyst was sufficient to achieve high conversion even at such low concentrations. $^{17 a}$

The ${ }^{1} \mathrm{H}$ NMR spectra of $\mathbf{M O}_{\mathbf{4}}$, carrying isopropyl side chains, as well as its precursor, $\mathbf{D O}_{4}$, are exemplarily depicted in Fig. 2. Spectrum A, showing $\mathbf{M O}_{4}$ before the cyclization reaction, shows the characteristic signals of the terminal double 


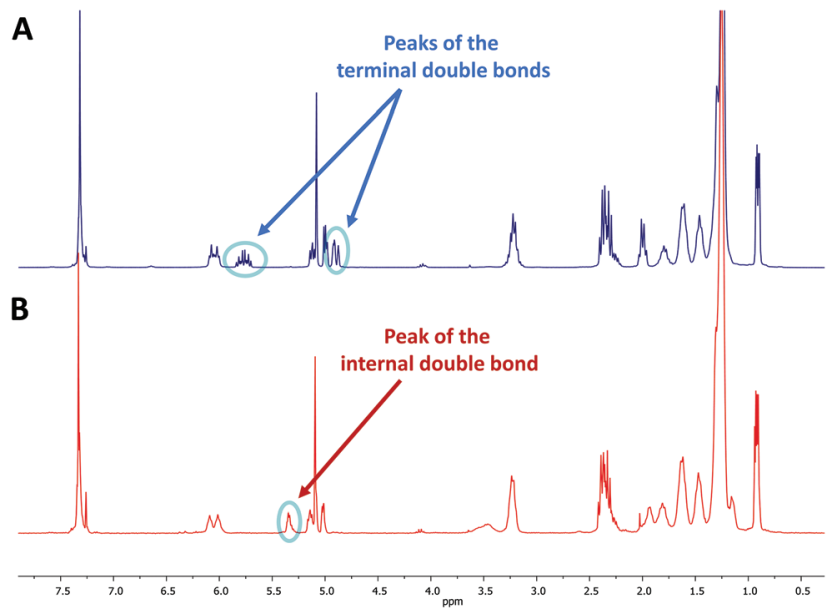

Fig. $2{ }^{1} \mathrm{H}$ NMR comparison of a $\mathrm{DO}_{4}(\mathrm{~A})$ and a $\mathrm{MO}_{4}$ (B) carrying isopropyl side chains. In the first ${ }^{1} \mathrm{H}$ NMR spectrum, the signals of the terminal double bonds are clearly observed, whereas in the spectrum on the bottom, the signal of the newly formed internal double bond appears, and the two signals of the terminal double bond disappear completely, indicating full conversion towards $\mathrm{MO}_{4}$.

bonds, which disappear completely in spectrum $\mathbf{B}$ after cyclization, indicating full conversion toward the desired product. SEC analysis, on the other hand, revealed that the conversion of $\mathbf{D O}_{4}$ toward $\mathbf{M O}_{4}$ was only $91 \%$. Besides the product, traces of the ADMET side product are present as well as unreacted $\mathbf{D O}_{4}$, which remained in the crude product. The comparison of the NMR and SEC results thus clearly demonstrated the importance of SEC characterization for macromolecules exhibiting uniform size distribution, because only the latter provides sufficient resolution to prove the absence of tiny amounts of impurities, which is essential and can otherwise not be provided by any other characterization technique. The crude macrocyclic products $\mathbf{M O}_{\boldsymbol{X}}$ were thus characterized and compared by SEC-ESI-MS analysis. Surprisingly, the side chains did not influence the conversion significantly. The length of the oligomers, on the other hand, resulted in a considerable difference in conversion as observed by SEC (see Fig. 3): for the dimer $\left(\mathbf{D O}_{2}\right)$, nearly quantitative conversion towards the desired macrocycle $\left(\mathbf{M O}_{2}\right)$ was obtained, whereas lower conversions were observed when longer oligomers underwent the RCM reaction. For the decamer $\left(\mathbf{M O}_{\mathbf{1 0}}\right), 51 \%$ conversion towards the macrocycle was achieved, which is the lowest conversion compared to the smaller macrocycles $\left(\mathbf{M O}_{2-8}\right)$. Furthermore, ADMET oligomerization could be fully prevented in the case of $\left(\mathbf{D O}_{2}\right)$, whereas significant amounts of the ADMET side product were obtained in the RCM reaction of $\left(\mathbf{D O}_{\mathbf{1 0}}\right)(\mathrm{ca} .17 \%$, according to SEC analysis). Isolation of the macrocyclic product (from the linear oligomer and the ADMET side product) by column chromatography was not successful due to the similar polarity of the compounds. We also considered purification by preparative SEC, however the resolution was low compared to that of the oligomer-specific SEC columns used for characterization. Nonetheless, character-
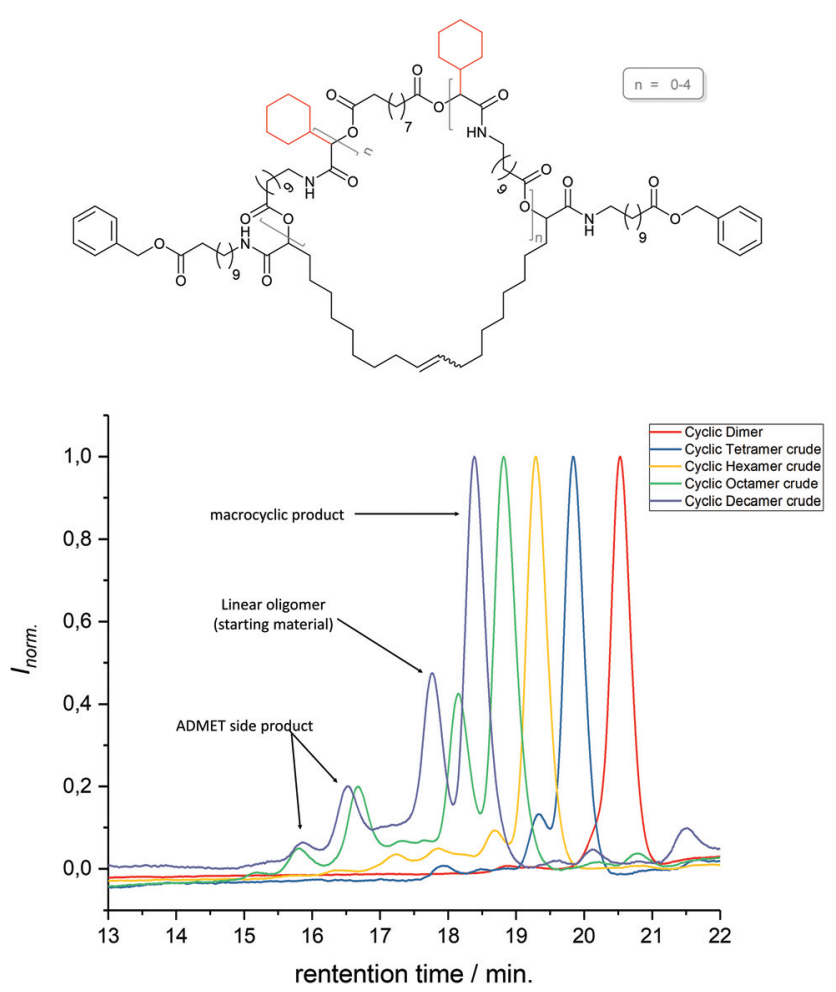

Fig. 3 Schematic representation of the structure of macrocycles with cyclohexyl side chains and sebacic acid as the core unit in different sizes (dimer - decamer), and the cooresponding SEC analysis results, revealing the influence of the size of the oligomer on the conversion towards the macrocycle. For the decamer, a detailed description of the obtained products is depicted exemplary. The different species were identified by SEC-ESI-MS analysis.

ization of the crude macrocyclic products by SEC-ESI-MS analysis was found to be adequate not only to determine the ratio between the linear starting material, macrocyclic product, and ADMET side product, but also to support the successful formation of the desired sequence-defined macrocycles arising from the advantageous combination of the ESI-MS and SEC data. For the decamer, for example, three peaks were observed, the one at a retention time of 14.36 belonging to the ADMET side product and the one at 15.33 minutes belonging to $\mathbf{D O}_{\mathbf{1 0}}$. The ESI-MS spectrum of the product fraction at 15.86 minutes showed a single isotopic distribution with a maximum at $1873.3949 \mathrm{~m} / \mathrm{z}$, which corresponds to the $\mathrm{Na}^{2+}$ adduct of the cyclized $\mathrm{MO}_{10}\left(\left[\mathrm{C}_{220} \mathrm{H}_{372} \mathrm{O}_{34} \mathrm{~N}_{10} \mathrm{Na}_{2}\right]^{2+}\right.$, see Fig. 4) It is noteworthy that large macrocycles, composed of up to $152 \mathrm{ring}$ backbone atoms, were obtained (see Fig. 5). In Fig. 6, the RCM towards two $\mathbf{M O}_{\mathbf{8}}$ with different side chains are compared regarding conversion toward the desired macrocycle and the ADMET side product, revealing low dependence on the sidechains. Furthermore, Fig. 5 reveals that the conversion toward the macrocycle is relatively independent of the applied sidegroups for different ring sizes. On the other hand, the conversion strongly depends on the size of the macrocycle. These trends confirm theoretical calculations. ${ }^{31}$ Interestingly, such conclusions could not be drawn if disperse oligomers were 


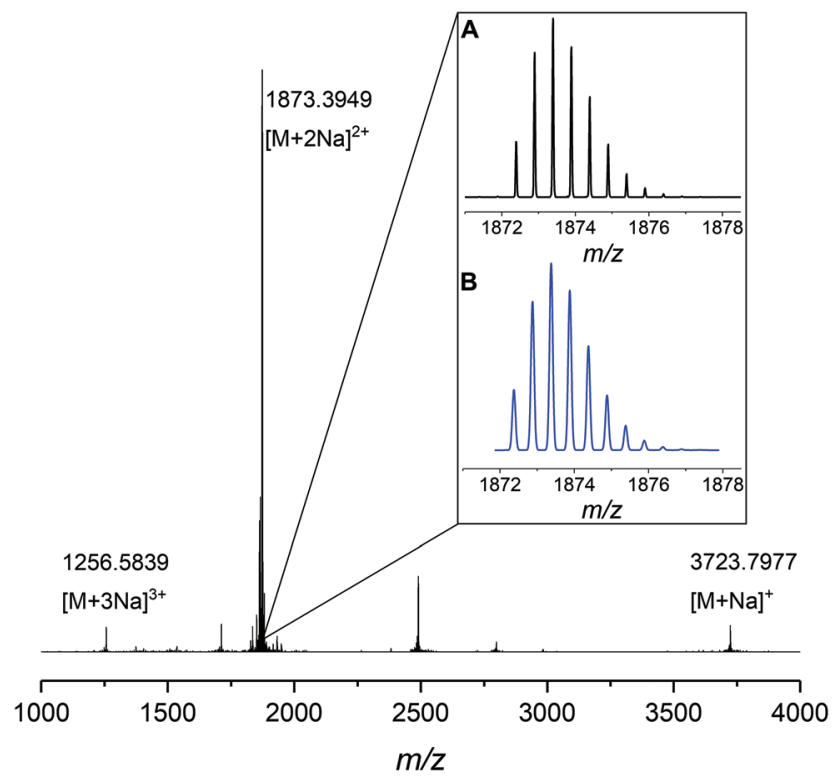

Fig. 4 SEC-ESI-MS analysis of the macrocyclic decamer bearing cyclohexyl side chains. The single, double and triple charged sodium cations are clearly observed. The expanded region (panel A) shows the apparent isotopic pattern (black) which was found to be in good agreement with the calculated one (blue, panel B), obtained by the program mmas.

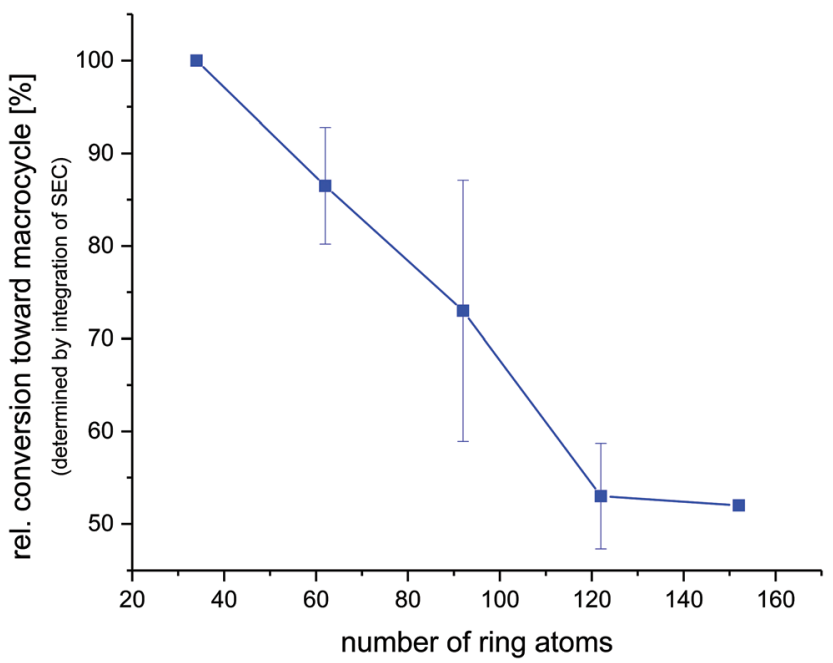

Fig. 5 Dependence of the oligomer size on the conversion toward the macrocycle. The mean values and standard deviation of the conversions for $\mathrm{MO}_{2,4,6,8,10}$ are displayed; the line is only drawn to guide the eye. $\mathrm{MO}_{2}$ and $\mathrm{MO}_{10}$ do not have a standard deviation since they were not synthesized with different side chains.

studied for their cyclization tendency, ${ }^{32}$ as (i) resolution in SEC would certainly be too poor to allow for proper integration (compare Fig. 3 and Fig. 6) and (ii) molecular weight dispersity would introduce a significant error in the abscissa of Fig. 5. Considering, for example, a typical dispersity of controlled radical polymerization of $D \sim 1.2$, a mass of $3724 \mathrm{~m} / \mathrm{z}$ with 152 ring atoms $\left(\mathbf{M O}_{\mathbf{1 0}}\right)$ would translate to a dispersity in ring size of 35 ring atoms. Macromolecules of uniform size, on the

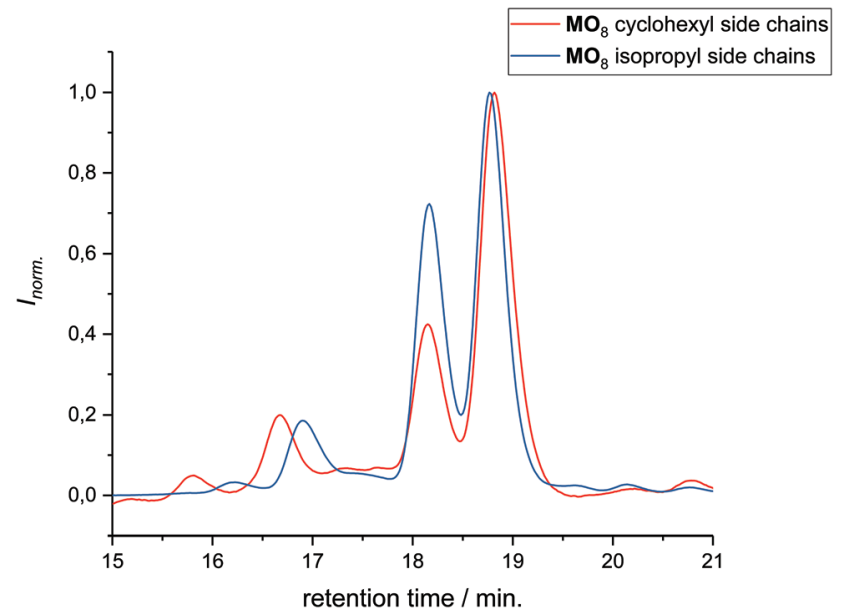

Fig. 6 Comparison of the conversion toward the macrocycles $\mathrm{MO}_{8}$ carrying different side chains, namely cyclohexyl and isopropyl by SEC analysis. The conversion is 57 and $49 \%$ for $\mathrm{MO}_{8}$ carrying cyclohexyl and isopropyl side chains, respectively. The peaks were identified by SEC-ESI-MS to be $\mathrm{MO}_{8}, \mathrm{DO}_{8}$, and the two ADMET side products $\left(\mathrm{DO}_{8}\right)_{2}$ and $\left(\mathrm{DO}_{8}\right)_{3}$, from higher to lower retention time.

other hand, allow for easy analysis by integration of the SEC traces if oligomer-specific columns with sufficient resolution are utilized.

\section{Conclusions}

In summary, we have shown the first example of a templatefree approach towards sequence-defined, large macrocycles. This is furthermore the first example of sequence-defined macromolecules that are employed for the synthesis of a polymer architecture other than linear macromolecules. The synthetic procedure allowed the introduction of different tailored side chains and long aliphatic backbones to the macrocyclic backbone. During RCM, clear trends were observed, offering the possibility to identify the limits of RCM regarding conversion and to determine clear structure-activity relationships, here the dependence of RCM on the length of the linear oligomer and on the side chains. Indeed, the side chains did not influence the conversion significantly, whereas the length of the oligomer greatly influenced the reaction selectivity. This study serves as a model and example of application possibilities of sequence-defined macromolecules of uniform size to determine quantitative structure property/activity relationships, which cannot be analyzed accurately if disperse systems are utilized. More precisely, we have demonstrated herein the limits and possibilities of RCM, which will be of interest to polymer and organic chemists, not only for metathesis reactions, but also for other ring-closing approaches.

\section{Conflicts of interest}

There are no conflicts to declare. 


\section{Acknowledgements}

Funding from the Deutsche Forschungsgemeinschaft (German Research Council, DFG) within the SFB 1176 "Structuring of Soft Matter" (project A3) is gratefully acknowledged. We thank Maximiliane Frölich, Rieke Schulte and the analytical team from KIT for analytical support, Lea Bayer for synthetic support, and Prof. Barner-Kowollik (KIT) and his group for access to SEC-ESI-MS equipment.

\section{Notes and references}

1 (a) S. C. Solleder, R. V. Schneider, K. S. Wetzel, A. C. Boukis and M. A. R. Meier, Macromol. Rapid Commun., 2017, 38, 1; (b) S. Martens, J. O. Holloway and F. E. Du Prez, in Sequence-Controlled Polymers, ed. J.-F. Lutz, Wiley VCH, Weinheim, 2018, p. 379; (c) N. Badi and J.-F. Lutz, Chem. Soc. Rev., 2009, 38, 3383; (d) J.-F. Lutz, J.-M. M. Lehn, E. W. Meijer and K. Matyjaszewski, Nat. Rev. Mater., 2016, $1,1$.

2 (a) L. Charles, C. Laure, J.-F. Lutz and R. K. Roy, Macromolecules, 2015, 48, 4319; (b) A. Al Ouahabi, M. Kotera, L. Charles and J.-F. Lutz, ACS Macro Lett., 2015, 4, 1077; (c) S. C. Solleder and M. A. R. Meier, Angew. Chem., Int. Ed., 2014, 53, 711; (d) S. C. Solleder, K. S. Wetzel and M. A. R. Meier, Polym. Chem., 2015, 6, 3201; (e) S. Martens, J. Van Den Begin, A. Madder, F. E. Du Prez and P. Espeel, J. Am. Chem. Soc., 2016, 138, 14182; (f) S. Martens, A. Landuyt, P. Espeel, B. Devreese, P. Dawyndt and F. Du Prez, Nat. Commun., 2018, 9, 4451.

3 (a) A. C. Boukis, K. Reiter, M. Frölich, D. Hofheinz and M. A. R. Meier, Nat. Commun., 2018, 9, 1439; (b) A. C. Boukis and M. A. R. Meier, Eur. Polym. J., 2018, 104, 32; (c) J.-F. Lutz, Acc. Chem. Res., 2013, 46, 2696; (d) H. M. Colquhoun and J.-F. Lutz, Nat. Chem., 2014, 6, 455; (e) J.-F. Lutz, Macromolecules, 2015, 48, 4759.

4 (a) R. K. Roy, A. Meszynska, C. Laure, L. Charles, C. Verchin and J.-F. Lutz, Nat. Commun., 2015, 6, 7237; (b) D. Karamessini, S. Poyer, L. Charles and J.-F. Lutz, Macromol. Rapid Commun., 2017, 38, 1700426.

5 C. Gerke, M. F. Ebbesen, D. Jansen, S. Boden, T. Freichel and L. Hartmann, Biomacromolecules, 2017, 18, 787.

6 (a) J.-F. Lutz, M. Ouchi, D. R. Liu and M. Sawamoto, Science, 2013, 341, 1238149; (b) J.-F. Lutz, ACS Macro Lett., 2014, 3, 1020.

7 (a) J.-F. Lutz, in Sequence-Controlled Polymers, ed. J.-F. Lutz, Wiley VCH, Weinheim, 1st edn, 2018, p. 1; (b) J.-F. Lutz, Macromol. Rapid Commun., 2017, 1700582.

8 (a) P. Espeel, L. L. G. Carrette, K. Bury, S. Capenberghs, J. C. Martins, F. E. Du Prez and A. Madder, Angew. Chem., Int. Ed., 2013, 52, 13261; (b) C. Alabi, in Sequence-Controlled Polymers, ed. J.-F. Lutz, Wiley VCH, Weinheim, 1st edn., 2018, p. 159; (c) T. T. Trinh, C. Laure and J.-F. Lutz, Macromol. Chem. Phys., 2015, 216, 1498; (d) J. C. Barnes, D. J. C. Ehrlich, A. X. Gao, F. A. Leibfarth, Y. Jiang, E. Zhou,
T. F. Jamison and J. A. Johnson, Nat. Chem., 2015, 7, 810; (e) J. O. Holloway, C. Mertens, F. E. Du Prez and N. Badi, Macromol. Rapid Commun., 2018, 1800685.

9 (a) S. C. Solleder and M. A. R. Meier, Angew. Chem., Int. Ed., 2014, 53, 711; (b) R. Kakuchi, Angew. Chemie - Int. Ed., 2014, 53, 46; (c) L. Yang, Z. Zhang, B. Cheng, Y. You, D. Wu and C. Hong, Sci. China: Chem., 2015, 58, 1734; (d) S. C. Solleder, D. Zengel, K. S. Wetzel and M. A. R. Meier, Angew. Chemie - Int. Ed., 2016, 55, 1204; (e) S. C. Solleder, S. Martens, P. Espeel, F. E. Du Prez and M. A. R. Meier, Chem. - Eur. J., 2017, 23, 13906; (f) Y.-H. Wu, J. Zhang, F.-S. Du and Z.-C. Li, ACS Macro Lett., 2017, 6, 1398; (g) Z. Zhang, Y. You and C. Hong, Macromol. Rapid Commun., 2018, 1800362; (h) W. Konrad, F. R. Blößer, K. S. Wetzel, A. C. Boukis, M. A. R. Meier and C. Barner-Kowollik, Chem. - Eur. J., 2018, 24, 3413.

10 M. Passerini, Gazz. Chim. Ital., 1921, 51, 126.

11 B. A. Laurent and S. M. Grayson, Chem. Soc. Rev., 2009, 38, 2202.

12 (a) Y. Tezuka and H. Oike, J. Am. Chem. Soc., 2001, 123, 11570; (b) K. Endo, in New Frontiers in Polmer Science, ed. S. Kobayashi, Springer-Verlag, Berlin Heidelberg, 2008, p. 121.

13 (a) M. Schappacher and A. Deffieux, Makromol. Chem., Rapid Commun., 1991, 12, 447; (b) L. Rique-Lubet, M. Schappacher and A. Deffieux, Macromolecules, 1994, 27, 6318; (c) Y. Tezuka and F. Ohashi, Macromol. Rapid Commun., 2005, 26, 608; (d) L. Wang, M. O. Vysotsky, A. Bogdan, M. Bolte and V. Böhmer, Science, 2004, 304, 1312.

14 (a) D. Geiser and H. Höcker, Macromolecules, 1980, 13, 653; (b) G. Hild, A. Kohler and P. Rempp, Eur. Polym. J., 1980, 16, 525; (c) J. Roovers and P. M. Toporowski, Macromolecules, 1983, 16, 843.

15 (a) Y. Li, X. Qiu and Z.-X. Jiang, Org. Process Res. Dev., 2015, 19, 800; (b) X. Lv, X. Zheng, Z. Yang and Z.-X. Jiang, Org. Biomol. Chem., 2018, 16, 8537; (c) H. Jacobson and W. H. J. Stockmayer, Chem. Phys., 1950, 18, 1600; (d) C. W. Bielawski, D. Benitez and R. H. Grubbs, Science, 2002, 297, 2041; (e) C. W. Bielawski, D. Benitez and R. H. Grubbs, J. Am. Chem. Soc., 2003, 125, 8424.

16 R. H. Grubbs, S. J. Miller and G. C. Fu, Acc. Chem. Res., 1995, 28, 446.

17 (a) A. Deiters and S. F. Martin, Chem. Rev., 2004, 104, 2199; (b) C. Heinis, Nat. Chem. Biol., 2014, 10, 696.

18 S. K. Armstrong, J. Chem. Soc., Perkin Trans. 1, 1998, 371.

19 I. Nakamura and Y. Yamamoto, Chem. Rev., 2004, 104, 2127.

20 (a) J. N. Lambert, J. P. Mitchell and K. D. Roberts, J. Chem. Soc., Perkin Trans. 1, 2001, 471; (b) S. A. Kates, N. A. Solé, C. R. Johnson, D. Hudson, G. Barany and F. Albericio, Tetrahedron Lett., 1993, 34, 1549; (c) J. J. Storhoff and C. A. Mirkin, Chem. Rev., 1999, 99(7), 1849; (d) M. Göritz and R. Krämer, J. Am. Chem. Soc., 2005, 127, 18016.

21 E. M. Driggers, S. P. Hale, J. Lee and N. K. Terrett, Nat. Rev. Drug Discovery, 2008, 7, 608. 
22 J. Shi and D. E. Bergstrom, Angew. Chem., Int. Ed. Engl., 1997, 36, 111.

23 L. Zhang, A. J. Stephens, A. L. Nussbaumer, J. F. Lemonnier, P. Jurček, I. J. Vitorica-Yrezabal and D. A. Leigh, Nat. Chem., 2018, 10, 1083.

24 R. D. Adams, M. Huang, W. Huang and J. A. Queisser, J. Am. Chem. Soc., 1996, 118, 9442.

25 B. A. Laurent and S. M. Grayson, J. Am. Chem. Soc., 2006, 128, 4238.

26 (a) M. Mayor and C. Didschies, Angew. Chem., Int. Ed., 2003, 42, 3176; (b) D. V. Kondratuk, L. A. Perdigão, A. M. Esmail, J. N. O'shea, P. H. Beton and H. L. Anderson, Nat. Chem., 2015, 7, 317.

27 (a) E. Wasserman, J. Am. Chem. Soc., 1960, 82, 4433; (b) G. Gil-Ramírez, D. A. Leigh and A. J. Stephens, Angew. Chem., 2015, 127, 6208; (c) M. Raza Shah, S. Duda,
B. Müller, A. Godt and A. Malik, J. Am. Chem. Soc., 2003, 125, 5408; (d) S. Duda and A. Godt, Eur. J. Org. Chem., 2003, 2003, 3412; (e) A. Godt, Eur. J. Org. Chem., 2004, 2004, 1639.

28 M. Porel, D. N. Thornlow, N. N. Phan and C. A. Alabi, Nat. Chem., 2016, 8, 590.

29 (a) J. A. Berrocal, S. Albano, L. Mandolini and S. Di Stefano, Eur. J. Org. Chem., 2015, 34, 7504; (b) G. C. Vougioukalakis and R. H. Grubbs, Chem. Rev., 2010, 110, 1746.

30 (a) P. A. Fokou and M. A. R. Meier, J. Am. Chem. Soc., 2009, 131, 1664; (b) P. A. Fokou and M. A. R. Meier, Macromol. Rapid Commun., 2010, 31, 368.

31 (a) S. Di Stefano and G. Ercolani, Adv. Phys. Org. Chem., 2016, 50, 1; (b) S. Di Stefano and L. Mandolini, Chem. Phys. Phys. Chem., 2019, 21, 955.

32 M. A. R. Meier and C. Barner-Kowollik, Adv. Mater., 2018, 1806027. 